\title{
Preliminary Design and Analysis of an In-plane PRSEUS Joint
}

\author{
Andrew E. Lovejoy ${ }^{1}$ \\ NASA Langley Research Center, Hampton, VA 23681 \\ and \\ Steven Poplawski ${ }^{2}$ \\ University of Michigan, Ann Arbor, MI 48109
}

\begin{abstract}
As part of the National Aeronautics and Space Administration's (NASA's) Environmentally Responsible Aviation (ERA) program, the Pultruded Rod Stitched Efficient Unitized Structure (PRSEUS) has been designed, developed and tested. However, PRSEUS development efforts to date have only addressed joints required to transfer bending moments between PRSEUS panels. Development of in-plane joints for the PRSEUS concept is necessary to facilitate in-plane transfer of load from PRSEUS panels to an adjacent structure, such as from a wing panel into a fuselage. This paper presents preliminary design and analysis of an in-plane PRSEUS joint for connecting PRSEUS panels at the termination of the rod-stiffened stringers. Design requirements are provided, the PRSEUS blade joint concept is presented, and preliminary design changes and analyses are carried out to examine the feasibility of the proposed in-plane PRSEUS blade joint. The study conducted herein focuses mainly on the PRSEUS structure on one side of the joint. In particular, the design requirements for the rod shear stress and bolt bearing stress are examined. A PRSEUS blade joint design was developed that demonstrates the feasibility of this in-plane PRSEUS joint concept to terminate the rod-stiffened stringers. The presented design only demonstrates feasibility, therefore, some areas of refinement are presented that would lead to a more optimum and realistic design.
\end{abstract}

\section{Introduction}

$\mathrm{T}$ he Pultruded Rod Stitched Efficient Unitized Structure (PRSEUS) ${ }^{1}$ concept, developed by the Boeing Company, has been extensively studied as part of the National Aeronautics and Space Administration's (NASA's) Environmentally Responsible Aviation (ERA) Project as it applies to a hybrid-wing body (HWB) aircraft. PRSEUS was chosen at the primary structural concept in ERA because it is enabling technology for the pressurized, noncircular center portion of the HWB, in which the majority of the structural panels are subjected to bi-axial, inplane loads in addition to the internal cabin pressure. The building block approach has been used to design, analyze, build and test HWB PRSEUS structural components leading to an $80 \%$ scale center portion of the HWB as shown in Fig. 1 (identified as the Multi-Bay Pressure Box in the lower right portion of the figure). An important aspect of this test specimen is that the included joints are used to transfer moments between adjacent structural panels to counteract the bending loads. As a risk reduction measure, a cube fabricated entirely of PRSEUS panels (Pressure Cube shown in Fig. 1) was designed and tested. ${ }^{2}$ However, both the HWB and other configuration concepts will have need of in-plane joints to connect PRSEUS structure. In particular, the outboard wing of the HWB or the wing of a conventional tube-and-wing aircraft will need to be connected to the main body of the aircraft. The in-plane joint consists of the PRSEUS structure on one side of the joint, and the structure to which the PRSEUS structure is being attached (which may or may not be PRSEUS structure) and any additional structure or splice plates needed to transfer load across the joint. The current paper focuses on the preliminary design and analysis of an in-plane rod-

\footnotetext{
${ }^{1}$ Senior Aerospace Engineer, Structural Mechanics \& Concepts Branch, MS 190, Senior Member AIAA.

${ }^{2}$ Formerly Graduate Student, Atmospheric, Oceanographic and Space Sciences, Space Research Building, 2455 Hayward Street. 
stiffened stringer joint, focusing on the PRSEUS structure side of the joint, and how the PRSEUS construction can be modified to facilitate in-plane bolted joints.

\section{The PRSEUS concept}

PRSEUS is an integral structural concept ${ }^{3-6}$ that evolved out of stitching technology development from a NASABoeing program in the 1990's whereby the PRSEUS skins, frames, stringers and tear straps are all stitched together, then infused and cured in an out-of-autoclave process. ${ }^{1}$ An expanded view of a PRSEUS stiffener intersection is shown in Fig. 2. The key to the PRSEUS concept is the pre-cured, pultruded rod that is contained within the top of the stringer stacks, and which passes through the frames, providing an uninterrupted load path. At the same time, the full depth frame stiffener is also continuous, except for the slot in the frame, or key-hole, through which the stringer passes, providing an uninterrupted load path in the direction perpendicular to the stringer. These efficient structural stiffening members provide the majority of the panel stiffness, permitting the use of minimum skin thickness for many applications. However, in wing applications, the skin is expected to be thick at the wing root, and the rodstringers will be oriented in the span-wise direction. Since the PRSEUS concept has been primarily studied with thin skins, with well defined loads, a thin skin design is used for this preliminary in-plane joint study.

The configuration of a typical PRSEUS panel used in many of the building block tests was used for the initial inplane joint evaluation. A typical panel is fabricated from warp-knit fiber architecture stacks of dry AS4 carbon fiber, pultruded carbon fiber rods and Rohacell foam. The prekitted basic stacks have a stacking sequence of [45/$\left.45 / 0_{2} / 90 / 0_{2} /-45 / 45\right]_{\mathrm{T}}$, which results in a stack thickness of approximately 0.052 inches. The pultruded rods are Toray unidirectional T800 fiber with a 3900-2B resin, and the frame stiffeners are filled with the Rohacell foam. Stringer and frame cross-sections are shown in Fig. 3. In the figure, the distinct regions of the stringer stack are identified, namely, the flange that is parallel to the skin, the wrap that is the portion of the stack surrounding the rod, and the web that is the portion between the flange and wrap and is perpendicular to the skin. Nominal stringer and frame heights, measured from the outer mold line, are 1.49 and 6.0 inches, respectively. The skin, frames, and stringers are stitched into a dry preform that is infused with HexFlow VRM 34 resin using Boeing's Controlled Atmospheric Pressure Resin Infusion (CAPRI) process. ${ }^{1}$ The skin utilizes the minimum skin gauge of one stack, or 0.052 inches. Typical stringer spacing is 6 inches, and typical frame spacing is 20 inches.

\section{In-plane PRSEUS Joint Design}

An in-plane PRSEUS joint is required to transfer in-plane loads from a PRSEUS panel to an adjacent structure, and can be in the stringer or frame direction. This paper focuses on a stringer in-plane joint, as the stringers are expected to be oriented span-wise in a typical wing-type panel. Therefore, the joint is required to provide a load path by which the loads carried by the skin and stringers are transferred to the adjacent structure. In the case of PRSEUS, the pultruded rod is a major load-carrying component. Unfortunately, because the rod is unidirectional material, and because the rod can be of similar diameter to the fasteners that would be used to connect a joint, it is not possible to provide a direct load path from the rod, through the bolts, and across the joint. Therefore, it is necessary to develop additional structure around the stringer through which the rod loads can be passed across the joint. Since joints to attach blade stiffeners are commonly available (e.g. double lap), and due to the flat contour of the blade offering the advantage that the attaching joint structure is easily manufactured, a method to transition the PRSEUS stiffener to a blade configuration is considered first. The modified PRSEUS structure can then be attached to any adjacent structure using a conventional bolted joint. This paper includes information about the development of the entire joint, including all splice plates, bolt patterns, stack drops, etc., but focuses primarily on the rod-stiffener side of the joint.

The portion of the PRSEUS panel that will be included in the joint must be modified to create the structure necessary to construct the joint and pass the loads to the adjoining structure. A blade configuration can be developed from the PRSEUS configuration by encapsulating the stringer within additional composite material. In order to accomplish this task, the basic nine-ply stack defined above is used, along with additional two-ply stacks. These two-ply stacks have stacking sequences of [45/-45], [-45,45], [0/90] and [90/0], and are positioned so that their addition to the stringer creates a symmetric blade. Based on the stringer defined in Fig. 3a, the minimum thickness blade that can be developed has nominal thickness of 0.725 inches, with 18 stacks of material added to the stringer, as shown in Fig. 4. In the figure, the yellow stacks and the gray rod make up the typical PRSEUS stringer. The light blue stacks are the basic stack used in the skin, stringer tear strap, and stringer. The two-ply stacks are added as necessary to ensure a uniform nominal thickness along the height of the blade, and their orientations are shown in the figure. Note that the basic stacks used in the blade that extend the full height of the blade wrap atop the stringer

flange. Also shown in Fig. 4 are the possible locations of stitching lines that would be within the joint region of the 
PRSEUS preform. The dashed lines indicate the locations of the stitching that provides through-the-thickness connection of the blade joint stacks to the rest of the PRSEUS structure. The entire dry preform is then infused to create a unitized panel with an integral PRSEUS blade joint component that is the PRSEUS side of a bolted joint, eliminating the need for secondarily bonded structure to create the joint.

In addition to the build-up to create the blade, the skin in the bolted joint region was modified to increase its thickness for better bearing performance. As indicated above, the two stacks on either side of the blade wrap onto the stringer flange. In this initial design, these wrapped blade stacks, the stringer flange stacks and the stringer tear strap extend between the stringers atop the skin stack and, for this study, are assumed to be continuous in the entire 20 inches of the joint region for this study. Thus, initially, the stacks are added in order to construct the blade and skin build-ups to completely fill the space equivalent to that between two frames (see Fig. 5). The area covered by these additional stacks was reduced during the joint design as necessary, as described below. Further investigation into the manufacturing process is required to determine if these stacks can be constructed as defined analytically. Lastly, bolt rows were initially considered at four locations within the joint region, resulting in six rows of bolts as shown in Fig. 6. A row of bolts was located above the stringer rod (row 1), a row of bolts was located through the stringer web (row 2), a row of bolts was located along each stringer flange (rows 3 and 5), and a row of bolts was located along the center length of the skin bays (rows 4 and 6). Because it is advantageous for the bolts to be within a region having stitches, stitches will have to be added along the skin regions where the row 4 and 6 bolts are located. A 1.5-inch bolt spacing was chosen and the end bolts in each row were located 1 inch from the end of the joint region, for a total of 12 bolts per row (see Fig. 6). The initial sizes chosen for the bolts is 0.25 -inch diameter for the bolt row through the stringer web, and 0.375 -inch diameter bolts for the remaining rows. The details described above, and shown in Figs. $4-6$, constitute the initial baseline design. This baseline PRSEUS blade joint design was modified by removing stacks of material and bolts to generate a series of designs that were then analyzed to examine the response of the PRSEUS blade joint.

The design requirements for the blade joint take into account the following failure mechanisms:

1) Shear stress between the pultruded rod and the wrap.

2) Bearing stresses in the composite at the bolt locations.

3) Bearing bypass strains in the blade, flanges and skin.

4) Strains within the blade.

5) Strains within the skin and stringer flanges.

The most important of these failure mechanisms is the shear stress between the rod and the wrap, as that is the mechanism by which load within the rod is transferred to the blade. Since it has been seen in previous testing that, when failures occur, there is separation of the rod from the wrap, an investigation into the rod/wrap interface was performed to determine its strength. ${ }^{7}$ Using the data in the reference, a load of $5 \mathrm{kips} / \mathrm{in}$. was determined to be a conservative load carrying capability of the rod/wrap interface to be used in this study, which corresponds to an average shear stress at the interface of about $4.2 \mathrm{ksi}$, which is the allowable value used in this study. An evaluation of possible methods to increase this value is currently underway, and that data will be incorporated into the joint design as it becomes available.

\section{In-plane PRSEUS Joint Analysis}

While this paper addresses many aspects of the joint development, the information provided herein focuses primarily on the PRSEUS blade concept for an in-plane joint. The goal of the initial design and analysis was to examine the first two design requirements, namely the rod boundary shear stress and bearing stresses at the bolt locations. To evaluate these stresses, a simplified approach was taken, whereby the details of the remainder of the joint were ignored. A model was constructed containing a single bay width and two bay lengths of the typical current PRSEUS structure, such as presented in Section II.. The resulting finite element model is 40 inches long in the stringer direction and 6 inches wide, and is shown in Fig. 5. The blade and joint region of the model encompassed 20 inches of the model length, the entire width, and included both the blade build-up and skin buildup. To simplify the modeling for the initial analyses, the frame was not modeled since it would have little effect on the rod boundary shear stress and bolt load distribution. Solid finite elements were required in order to determine the shear stresses between the rod and wrap interface, so the entire PRSEUS structure was modeled using solid finite elements. The bolts were represented by beam elements that extended 0.125 inches beyond the surface of the composite, as shown in Fig 6. Simplified boundary conditions were applied directly to the bolt elements to represent the bolted connection. These simplified boundary conditions do not represent the flexibility of the total joint, but 
instead represent the PRSEUS portion of the joint to be affixed to a rigid body via the bolts, a condition considered adequate to initially investigate the response of the PRSEUS portion of the joint, and to permit development of initial joint architecture such as stack drops and bolt locations and sizes. All ends of the bolts were restrained from translation in the z-direction, which is aligned with the stringer's axial direction as seen in Fig. 5. The bolt beams were restrained from rotation about their axis by constraining rotation about the $\mathrm{x}$-axis or $\mathrm{y}$-axis for bolts in the blade portion or skin portion of the model, respectively. This boundary condition was necessary due to the lack of rotational degrees of freedom in the solid elements. Symmetry boundary conditions were applied along the long edges that are parallel to the stringer. Finally, a uniform displacement was applied in the z-direction at the end of the model representing the interior end of the panel.

Linear static analysis was performed using the ABAQUS finite element code. ${ }^{8}$ An arbitrary end displacement was applied to the model, and the resulting bolt loads were summed to provide a total load for the section. This value was compared to $80 \mathrm{kips}$, which was derived to be Design Ultimate Load (DUL) for a typical PRSEUS design from the data presented in Ref. 9. An end displacement of 0.14 inches corresponds to DUL for the baseline design and boundary conditions. This value was then applied in all analyses to determine the rod/wrap interface shear stress and the bolt bearing stresses. During the design process, the linear analysis results were scaled so that the total load obtained in the joint corresponds to DUL for all configurations. A plot of the rod/wrap interface shear stress for the baseline design and boundary conditions is shown in Fig. 7. It is seen that the magnitude of the average shear stress in the rod/wrap interface is less than $1.4 \mathrm{ksi}$ for the majority of the rod, well below the allowable value of $4.2 \mathrm{ksi}$. However, a peak absolute shear stress value of $16.39 \mathrm{ksi}$ is observed in a localized region at the end of the blade build-up. Additionally, the shear stress along the entire rod for a distance of about one inch from the joint/acreage interface region exceeds the allowable, so the design must be modified to ensure that the joint satisfies the design criteria. Next, the average bearing stress in the composite for bolt rows 1 through 4 is presented in Fig. 8 . Due to symmetry, the results for bolt rows 5 and 6 are omitted. Note also, that the distance is measured from the end of the PRSEUS blade, and thus 20 inches is at the junction of the baseline design blade build-up and the acreage, so that the bolt at 19 inches is closest to the acreage. The bearing stress values shown in the figure are typically compared to bolt-diameter-dependent bearing stress allowables, but for the purpose of this study a value of $100 \mathrm{ksi}$ is used for all bolts. It is seen that all except the bolt in rows 3 and 5 which is closest to the acreage are significantly lower than the allowable value. The maximum bearing stress value must be reduced to ensure that the joint satisfies the design requirement. Design changes involving stack drops, bolt pattern and including adjacent joint structure in order to reduce the maximum rod shear stress and bolt bearing stress in the composite are presented and discussed in the remainder of this section.

First, the effect of removing bolts from the acreage end of the joint was evaluated. Recall that the stress pattern shown in Fig. 8 demonstrated that the bearing stress is a maximum at the first bolt that is adjacent to the joint/acreage interface. Additionally, the location of the maximum rod shear stress is near the same end of the joint, and may be affected by the close proximity of the bolts. Using the same finite element model, the beams that represent the bolts were removed from all rows for the same distance from the joint end, one set at a time, and the structure re-analyzed. A typical bearing stress plot is shown is in Fig. 9 for the case where four sets of bolts have been removed. In total, analyses were performed for the cases where one set of bolts through seven sets of bolts were removed. The maximum bolt bearing stress for these designs is shown in Fig. 10, and the rod shear stress is shown in Fig. 11 where the green shaded region represents the region of acceptable shear stress. From Fig 10, it is seen that the maximum bearing stress initially drops, and then increases again as additional sets of bolts are removed. The change from decreasing to increasing bearing stress is due to the maximum bearing stress initially being in rows 3 and 5, and then transitioning to rows 4 and 6 as the additional sets of bolts are removed. The minimum value for the maximum bearing stress in the composite is seen to be approximately $100 \mathrm{ksi}$, which is right at the allowable value. It should be noted here that a check on bearing on any attachment joint structure indicates that the thickness of the connection structure, assuming it is aluminum alloy, results in a thickness between 0.2 and 0.25 inches. The need for such attachment thickness results in the inability of having a row of bolts between the rod and the stringer flange due to geometric constraints. Therefore, bolt row 2 has to be removed from the design. Next, Fig. 11 shows that the shear stress reduces as sets of bolts are removed, but that the shear stress remains significantly outside of the allowable range. Therefore, to reduce the maximum rod shear stress, it is necessary to modify the stiffness of the joint blade region.

The joint design study continued with the removal of bolt row 2 from the baseline design, with the resulting design being designated as baseline-2, and the bolt bearing and rod shear stresses were examined at DUL. In a manner consistent with the baseline design, sets of bolts were removed from baseline-2, and the resulting models analyzed. Fig. 12 shows the baseline- 2 maximum average bolt bearing stress and Fig. 13 shows the rod shear stress as sets of bolts are removed. It is seen from Fig. 12 that the maximum bearing stress has increased when compared 
to the baseline design, so that the allowable is exceeded for all bolt configurations considered for the baseline-2 design. While this maximum bearing stress value has to be reduced to have a viable design, it is known that adjusting the stiffness of the PRSEUS build-up region and introducing adjacent attachment structure can lead to this reduction by introducing flexibility into the system. Therefore, the maximum bearing stress is not considered to be a problem at this point. However, the rod shear stress shown in Fig. 13 indicates that the shear has become more of a problem. The magnitude of the maximum positive rod shear has dropped for all bolt configurations and is now within the allowable shear stress value. However, while the magnitude of the minimum negative shear stress with no bolts removed has reduced from $16.39 \mathrm{ksi}$ in the baseline design to $11.18 \mathrm{ksi}$ in the baseline-2 design, the remainder of the minimum negative rod shear stress magnitude values have increased with the removal of bolt sets in baseline2 , most by over $30 \%$ when compared to the baseline design, moving farther away from the allowable shear stress value. Therefore, the first and most important concern for the axial PRSEUS joint design, with a single row of bolts in the blade region, is to modify the design so that the maximum rod shear stress magnitude is reduced in order to satisfy the allowable value.

A series of stack terminations were examined as a means to reduce the magnitude of the maximum rod shear stress. A succession of stack-drop models were created by deleting elements from the baseline- 2 model such that stacks were removed from the blade thickness, but the full height of the blade build-up was retained. Figure 14 shows the baseline-2 design and Fig. 15 shows the baseline-3 design where stacks have been dropped, but where all sets of bolts are included in the three bolt rows. The rod shear stress distribution for each design is also shown in the figure. The maximum magnitude of the rod shear stress had been reduced from a value of $11.18 \mathrm{ksi}$ to $9.507 \mathrm{ksi}$, which is not a sufficient reduction in shear stress. In order to reduce the maximum magnitude of rod shear stress further, an additional stack drop was included and bolt sets were removed from the joint/acreage end of the joint. The magnitude of the shear stress continued to reduce. The baseline- 3 design with 4 sets of bolts removed is shown in Fig. 16, where it is seen that the maximum magnitude of the rod shear stress has reduced to 6.072 kips. To further reduce the rod shear stress, elements were removed from the portion of the blade above the rod to represent a tapered height. Additionally, another set of bolts was removed. The resulting design and rod shear stresses are shown in Fig. 17. The design has seven stack drops, four sets of bolts removed, and a taper that spans approximately seven inches from the joint/acreage interface. The maximum magnitude of the shear stress is seen to be $4.766 \mathrm{ksi}$, however, this is a localized peak value that covers a very small area of the rod. Since the remainder of the rod shear stresses is within the allowable value, this is considered to be an acceptable shear stress level. Next, the bolt bearing stress is shown in Fig. 18, where it is seen that the maximum bearing stress is approximately $135.5 \mathrm{ksi}$, significantly above the $100 \mathrm{ksi}$ allowable value. The design shown in Fig. 17 was then analyzed with aluminum attachment structure attached.

To analyze the joint including the PRSEUS structure and aluminum attachment structure, a shell model was developed to represent the aluminum structure, and incorporated into the design shown in Fig. 17. The complete model including the attachment structure is shown in Fig. 19, where an aluminum angle was added to either side of the blade, and an aluminum strap was added to the skin. The boundary conditions were removed from the bolt nodes, the aluminum structure was clamped at the end farthest from the joint/acreage interface, and symmetry conditions were applied to the long edges adjacent to the skin. All aluminum attachment structure elements were 0.25 inches thick. The resulting rod shear stress distribution and bolt bearing stresses are shown in Figs. 20 and 21, respectively. The maximum rod shear stress magnitude is $4.86 \mathrm{ksi}$, but as with the model where the boundary conditions were applied to the bolt ends, this value is a local maximum and the majority of the rod shear stress distribution is considered to be acceptable. Also, with the flexible attachment structure included in the joint, the maximum bolt bearing stress has been reduced to $83.1 \mathrm{ksi}$, which is significantly below the allowable value. Therefore, the design shown in Fig. 19 is considered to be acceptable to demonstrate that an in-line PRSEUS blade joint is feasible. However, since the frame was left out of the model, an additional boundary condition was added to the set of nodes on the outer mold line at the joint/acreage interface in which they were restrained from transverse displacement to represent the frame keeping the structure from bending in the frame direction. This model gives a maximum rod bearing stress magnitude of $4.625 \mathrm{ksi}$ and maximum bolt bearing stress of $77.9 \mathrm{ksi}$, both of which are smaller values than the model without the added support. These results indicate that including the frame in the model would have little effect on the response of the joint, and may actually be advantageous.

The PRSEUS blade concept developed herein includes a taper to the blade height. This tapered height joint design can be further developed by adding additional stitching along the taper. The blade joint concept contains stitching in the portion that is above the rod (recall Fig. 4). Including a stitching pattern that matches the contour that can be machined into the blade to create the height taper, as depicted by the curved black dashed line shown in Fig. 22 , can help prevent delamination along the length of the taper region. 


\section{Concluding Remarks}

This paper describes a design study assessing the feasibility of an in-plane PRSEUS blade joint to connect a PRSEUS structure to an adjoining structure. Several design requirements were presented, but the current study focused on the rod shear stress at the rod/wrap interface and the bolt bearing stress in the composite. In order to demonstrate that a PRSEUS blade joint could be designed such that these stresses would be below the allowables, the stacking sequence (stack drops), bolt pattern, and blade height taper were considered. A design was developed that satisfied the rod shear stress and bolt bearing stress requirements, and therefore demonstrates the feasibility of this in-plane PRSEUS blade joint concept.

The feasibility of the PRSEUS blade joint has been demonstrated, however, the design presented herein is not necessarily an optimum design. There are many aspects of the design that can benefit from further refinement and analysis, some of which are presented here. For the designs presented herein, all stack drops occurred on the outer surface of the blade. In general, it is advantageous to have the outer stack be continuous, by dropping interior stacks, so that stack edges are contained within the structure to aid in the suppression of delaminations. Also, bolt diameters were not varied in the current study, something that should be done to develop an optimum design in order to generate a more uniform bolt force profile. In this study, the joint structure adjacent to the PRSEUS structure was not modified, but rather a thickness for the material was determined from the baseline design, and the aluminum attachment plates were designed to have this uniform thickness. An optimum design could have these plates vary in thickness, and also in contour, as was done in Ref. 9 for the developed repair. Lastly, any path for future PRSEUS joint development should include development and execution of a testing program to validate joint designs.

\section{References}

${ }^{1}$ Velicki, A., "Damage Arresting Composites for Shaped Vehicles, Phase I Final Report," NASA CR-2009-215932, September 2009.

${ }^{2}$ Yovanov, Nicolette, Lovejoy, Andrew, Baraja, Jaime, and Gould, Kevin. "Design, Analysis and Testing of a PRSEUS Pressure Cube to Investigate Assembly Joints," 2012 Airworthiness \& Sustainment Conference, Baltimore, Maryland, April 2-5, 2012.

${ }^{3}$ Velicki, Alex, and Hansen, Dan, "Novel Blended Wing Body Structural Concepts," NRA-03-LaRC-02 Maturation for Advanced Aerodynamic and Structures Technologies for Subsonic Transport Aircraft: Phase I Final Report, July 13, 2004.

${ }^{4}$ Air Vehicle Technology Integration Program (AVTIP), Delivery Order 0059: Multi-role Bomber Structural Analysis, AFRL-VA-WP-TR-2006-3067, K. Hoffman, MAY 2006, Final Report for 14 December 2004 - 08 May 2006, AFRL-VA-WPTR-2006-3067.

${ }^{5}$ Karal, M., "AST Composite Wing Study - Executive Summary," NASA/CR-2001-210650, Prepared for NASA, Langley Research Center under Contract NAS1-20546, March 2001.

${ }^{6}$ Velicki, A. and Thrash, P. J., "Advanced Structural Concept Development Using Stitched Composites," 49th AIAA/ASME/ASCE/SHS/ASC Structures, Structural Dynamics, and Materials Conference, 7-10 April 2008, Schaumburg, IL, AIAA Paper 2008-2329.

${ }^{7}$ Wang, John T., Grenoble, Ray W. and Pickell, Robert D., "Structural Integrity Testing Method for PRSEUS Rod-Wrap Stringer Design," 53rd AIAA/ASME/ASCE/SHS/ASC Structures, Structural Dynamics, and Materials Conference, 23-26 April 2012, Honolulu, HI, AIAA Paper 2012-1861.

${ }^{8}$ Abaqus/Standard, Software Package, Ver. 6.9.1, SIMULIA, Providence, RI, 2009.

${ }^{9}$ Przekop, Adam, "Repair Concepts as Design Constraints of a Stiffened Composite PRSEUS Panel," 53rd AIAA/ASME/ASCE/SHS/ASC Structures, Structural Dynamics, and Materials Conference, 23-26 April 2012, Honolulu, HI, AIAA Paper 2012-1444. 


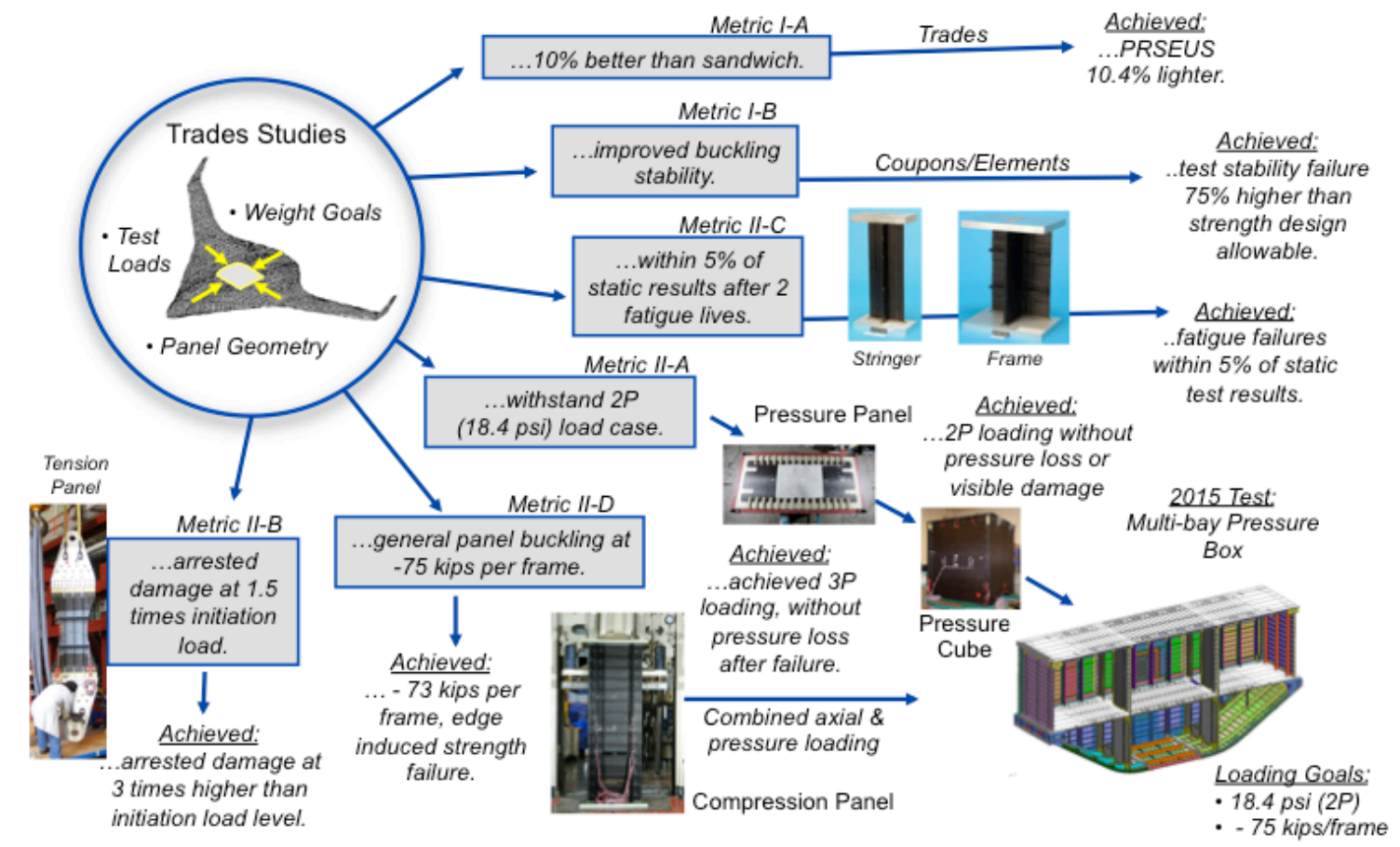

Figure 1. HWB structural development building block approach.

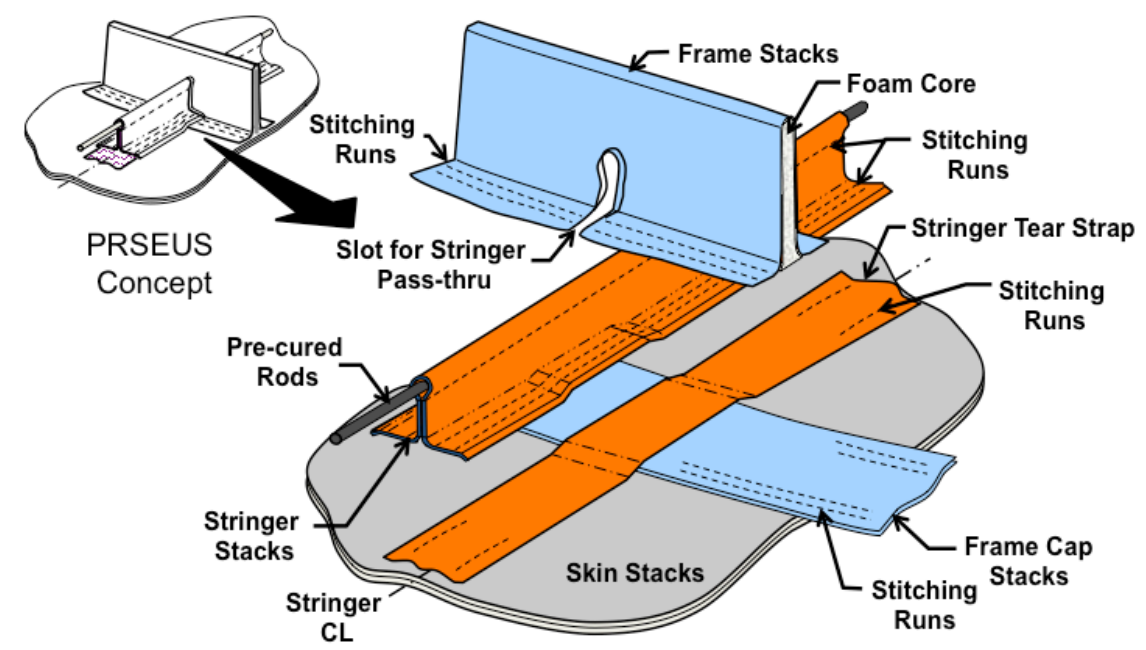

Figure 2. PRSEUS stiffener intersection expanded view. 


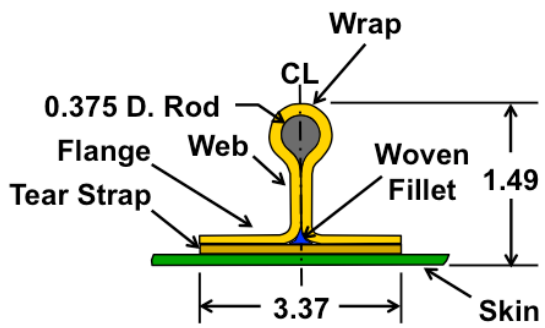

a) Stringer

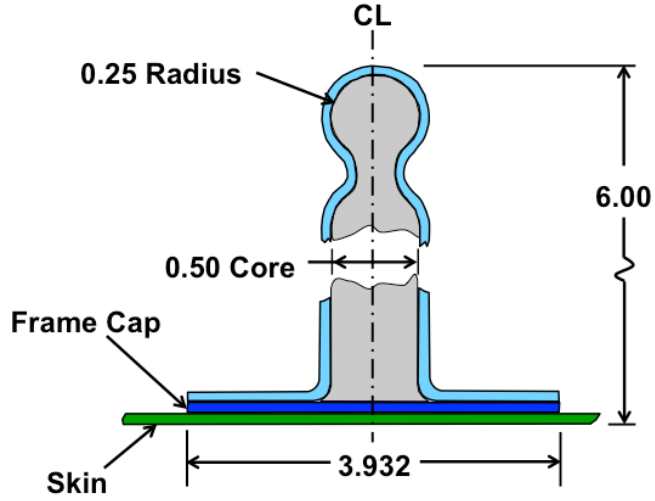

b) Frame

Figure 3. PRSEUS panel stringer and frame cross-sections. Dimensions are in inches.

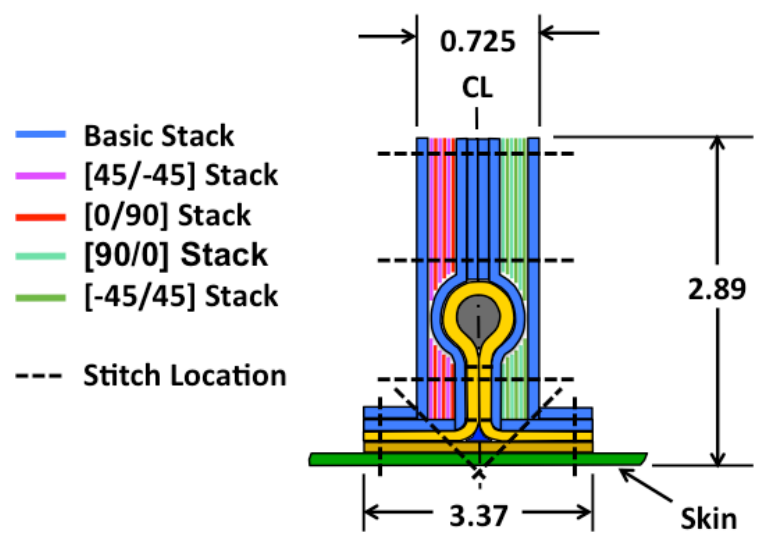

Figure 4. Sketch of PRESUS blade portion of joint concept. Dimensions are in inches. 


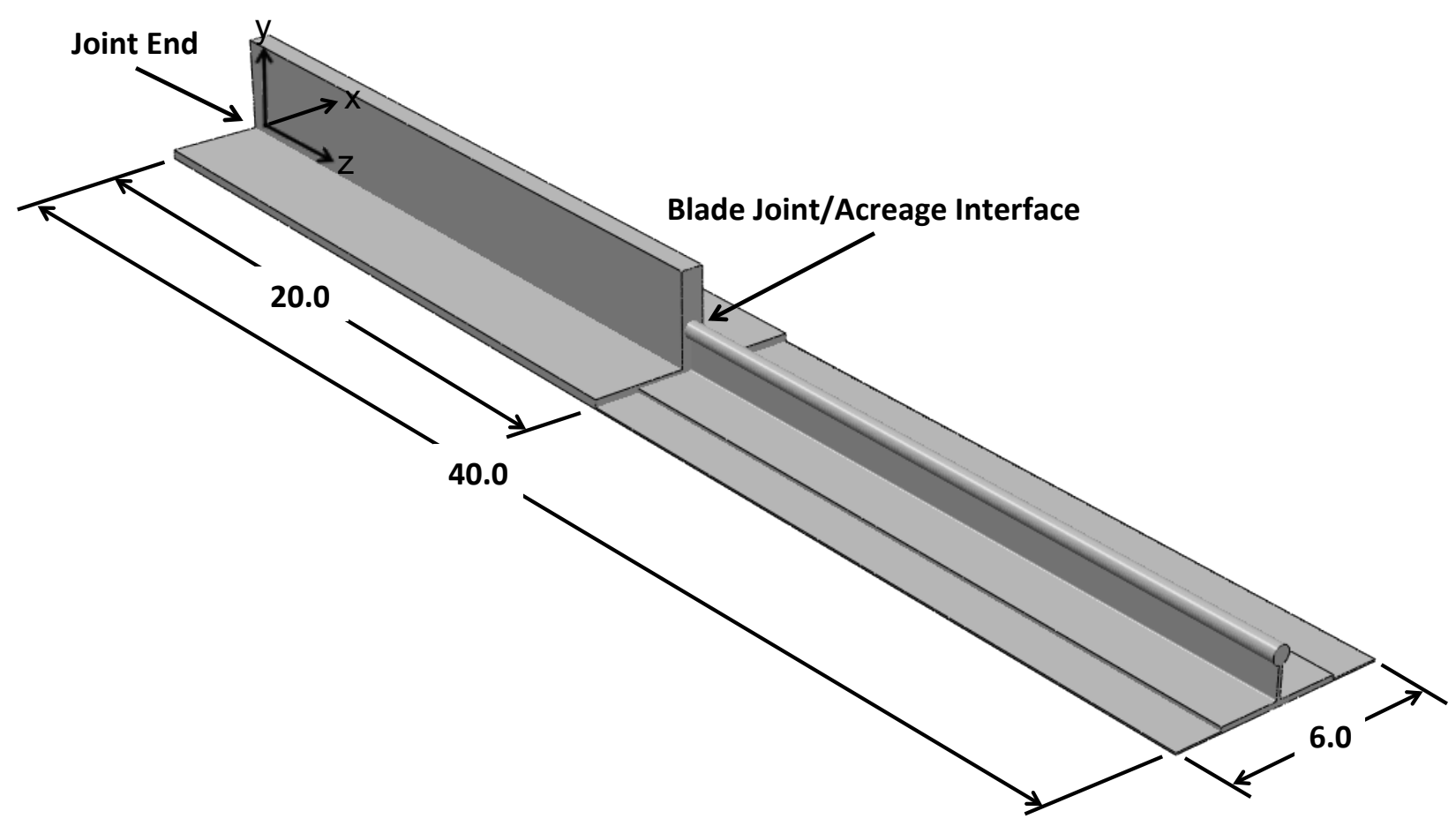

Figure 5. Overall dimensions (inches) of the model used for the PRSEUS-blade joint analysis.

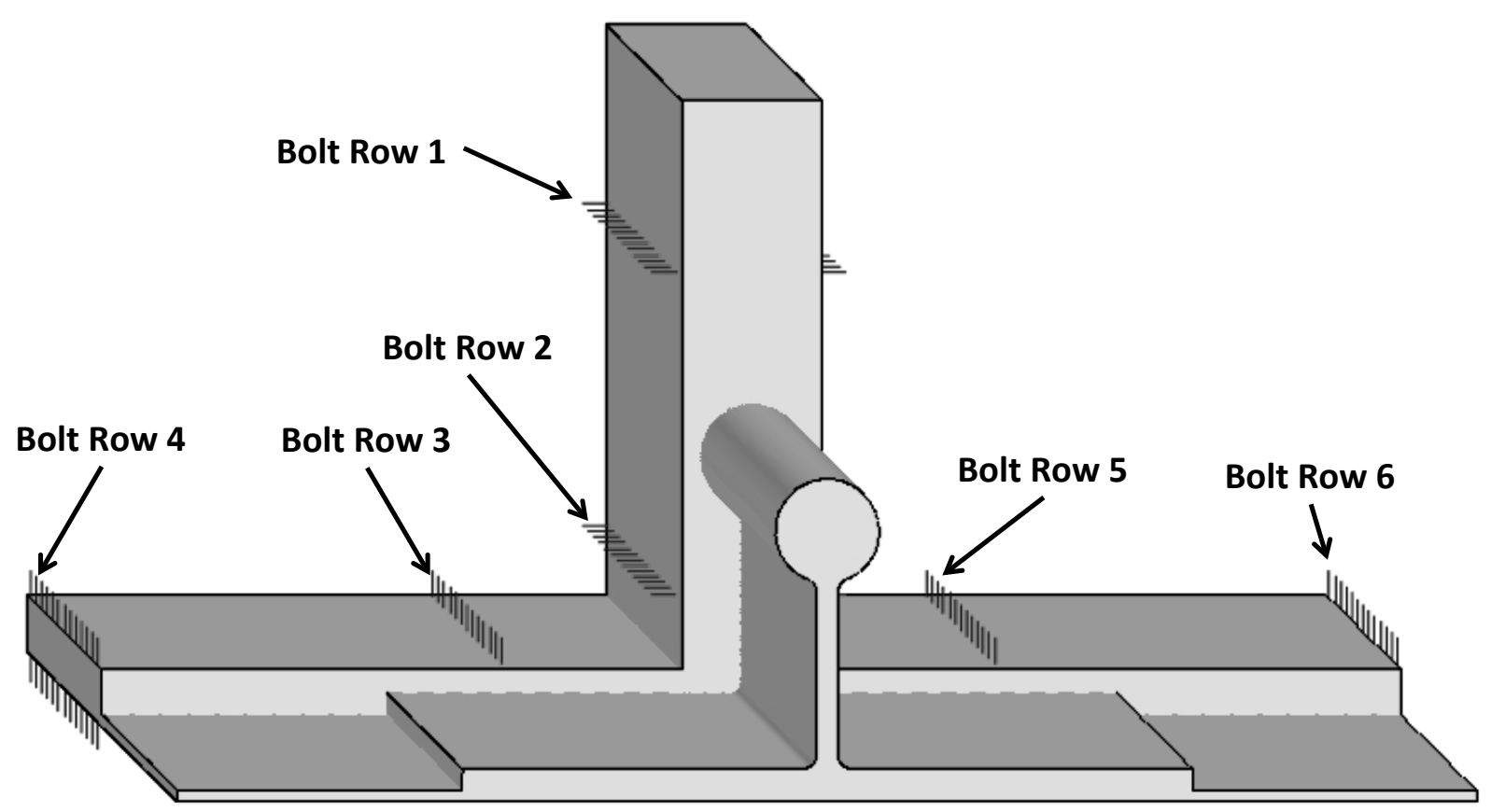

Figure 6. Bolt locations and bolt row numbering convention. 


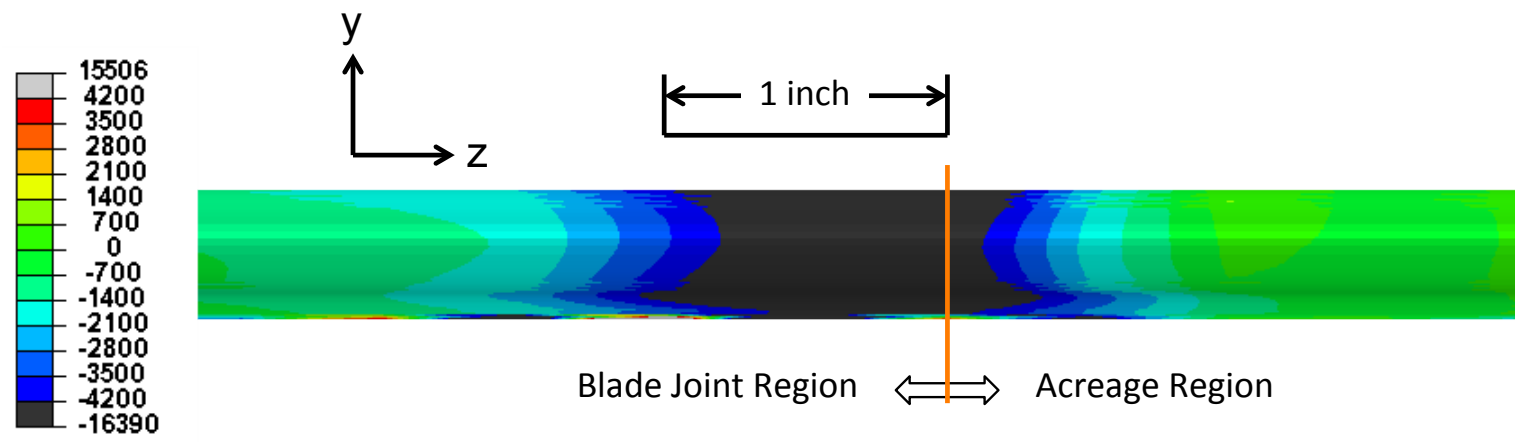

Figure 7. Rod/wrap shear stress (psi) at blade joint/acreage intersection (see Fig. 5).

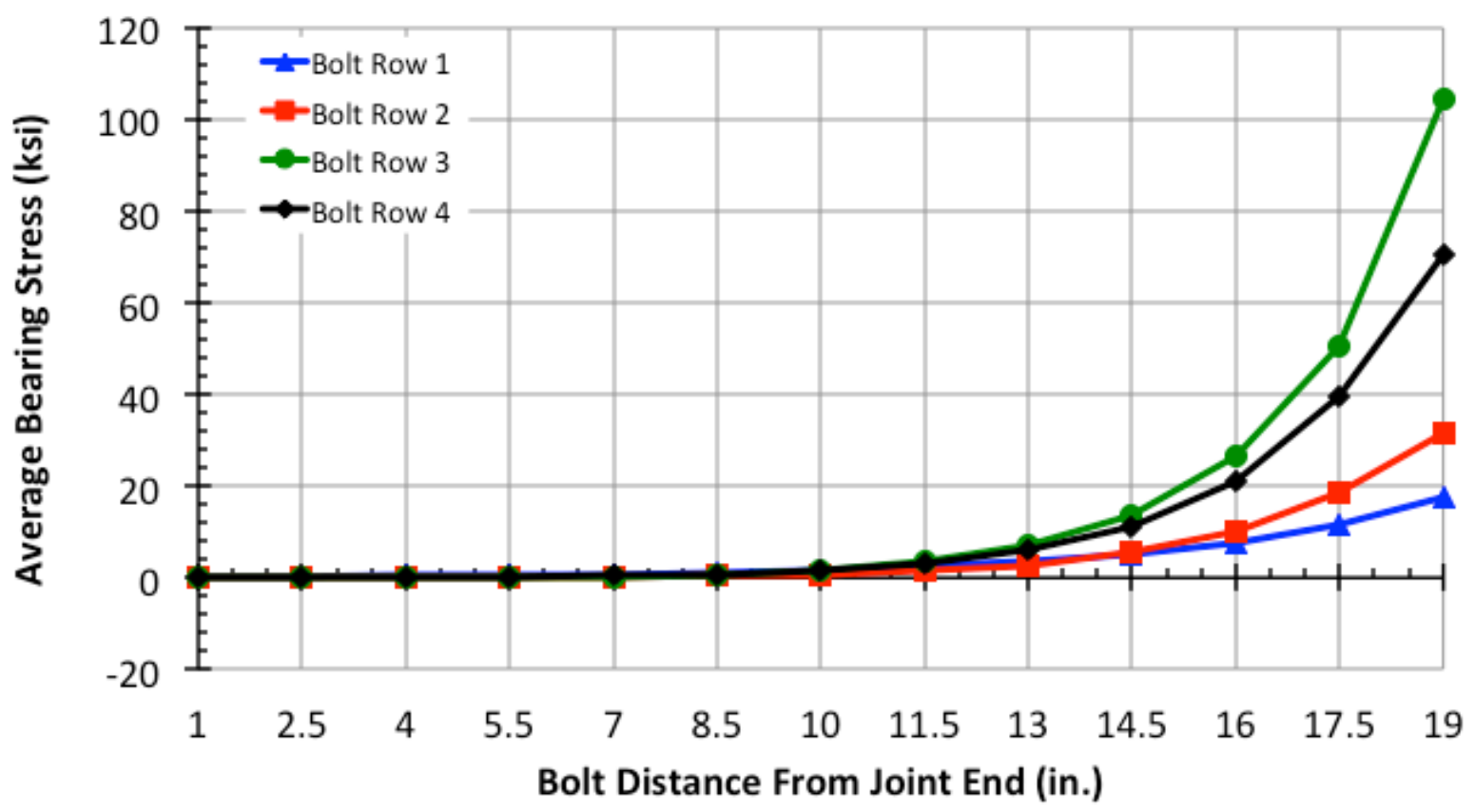

Figure 8. Average bearing stress in bolt rows 1 through 4, baseline design (in z-direction, see Fig. 5). 


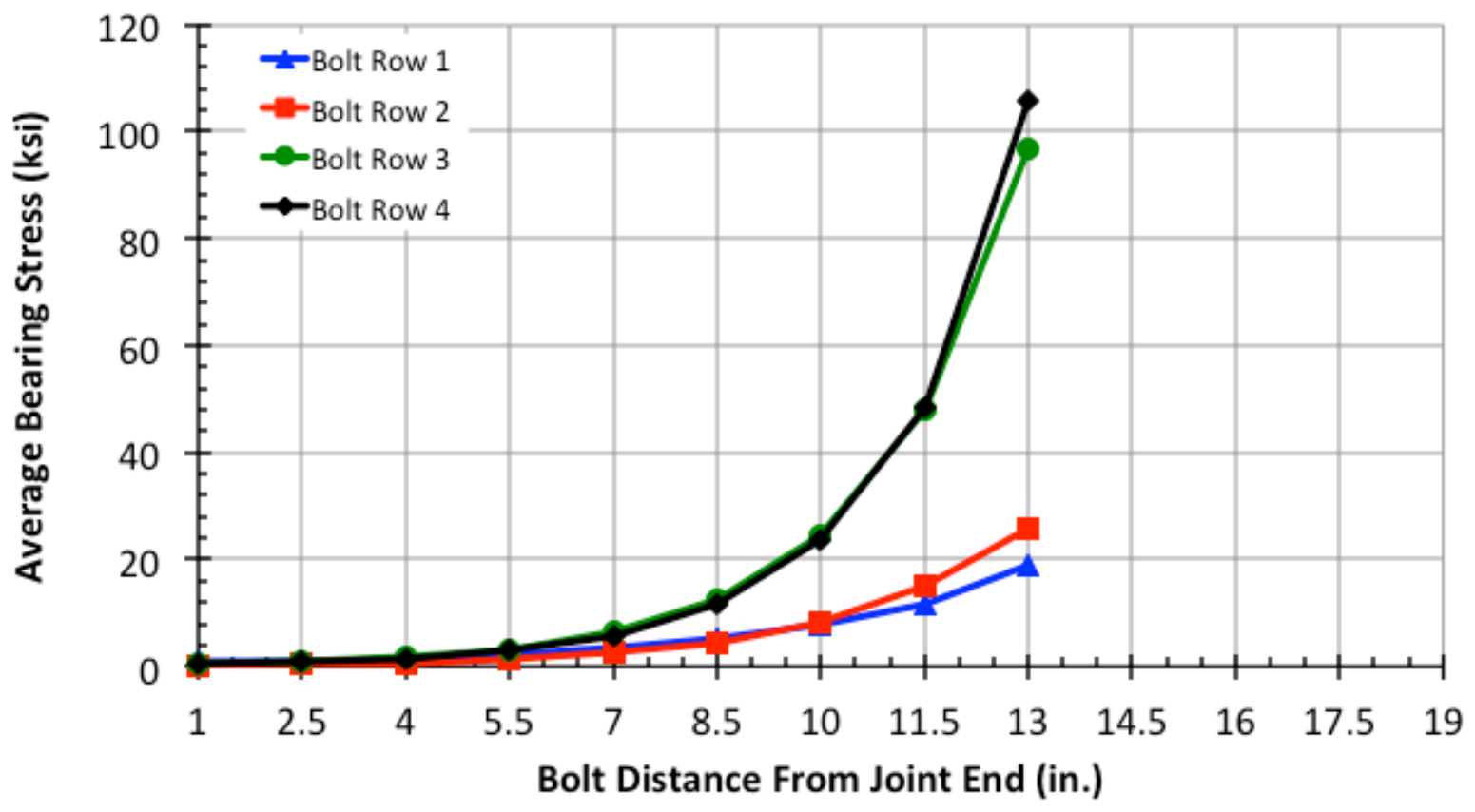

Figure 9. Average bearing stress in bolt rows 1 through 4, baseline design with 4 sets of bolts removed (in zdirection, see Fig. 5).

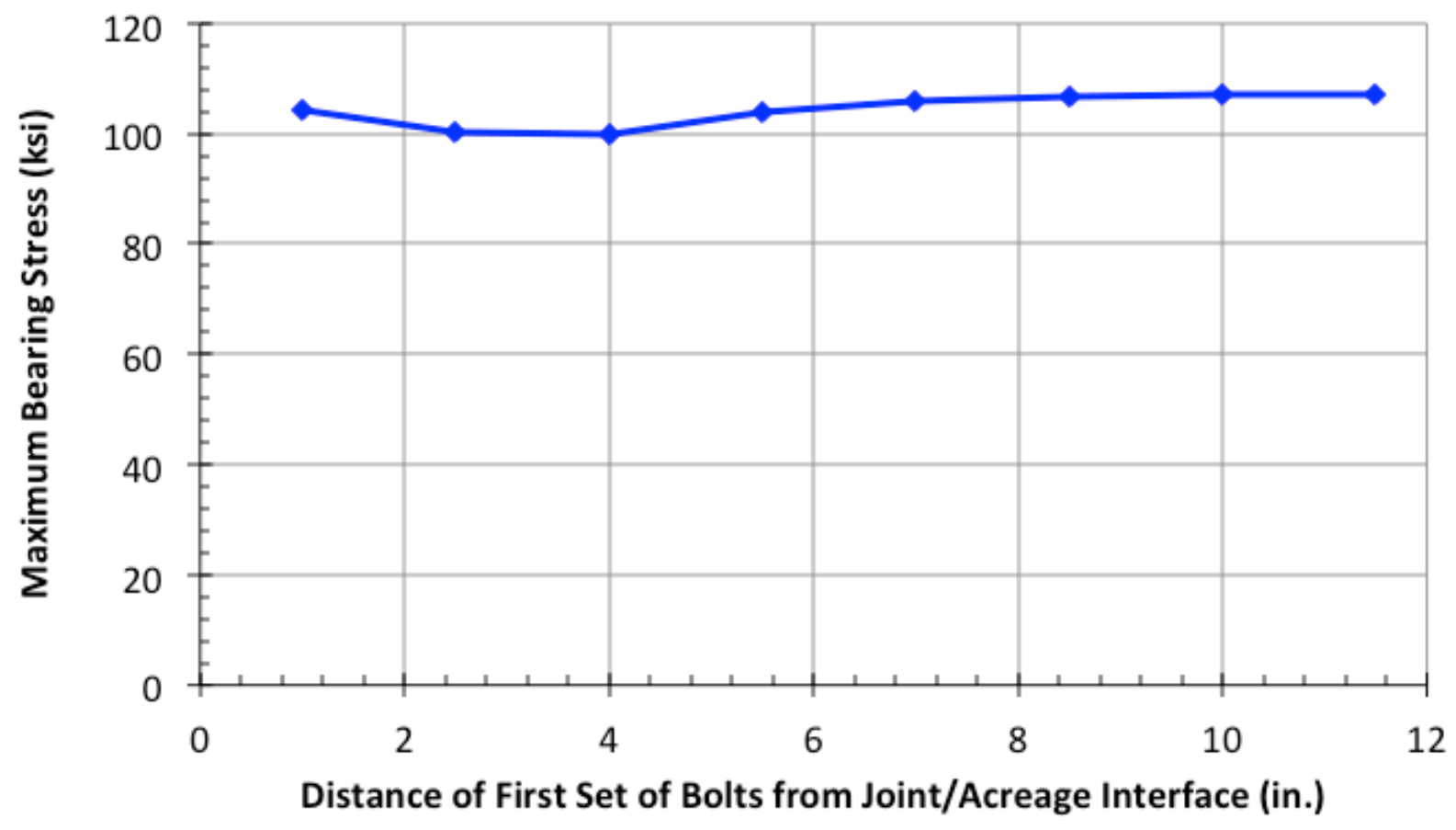

Figure 10. Maximum average bearing stresses for baseline design with zero to seven sets of bolts removed (in negative z-direction, see Fig. 5). 


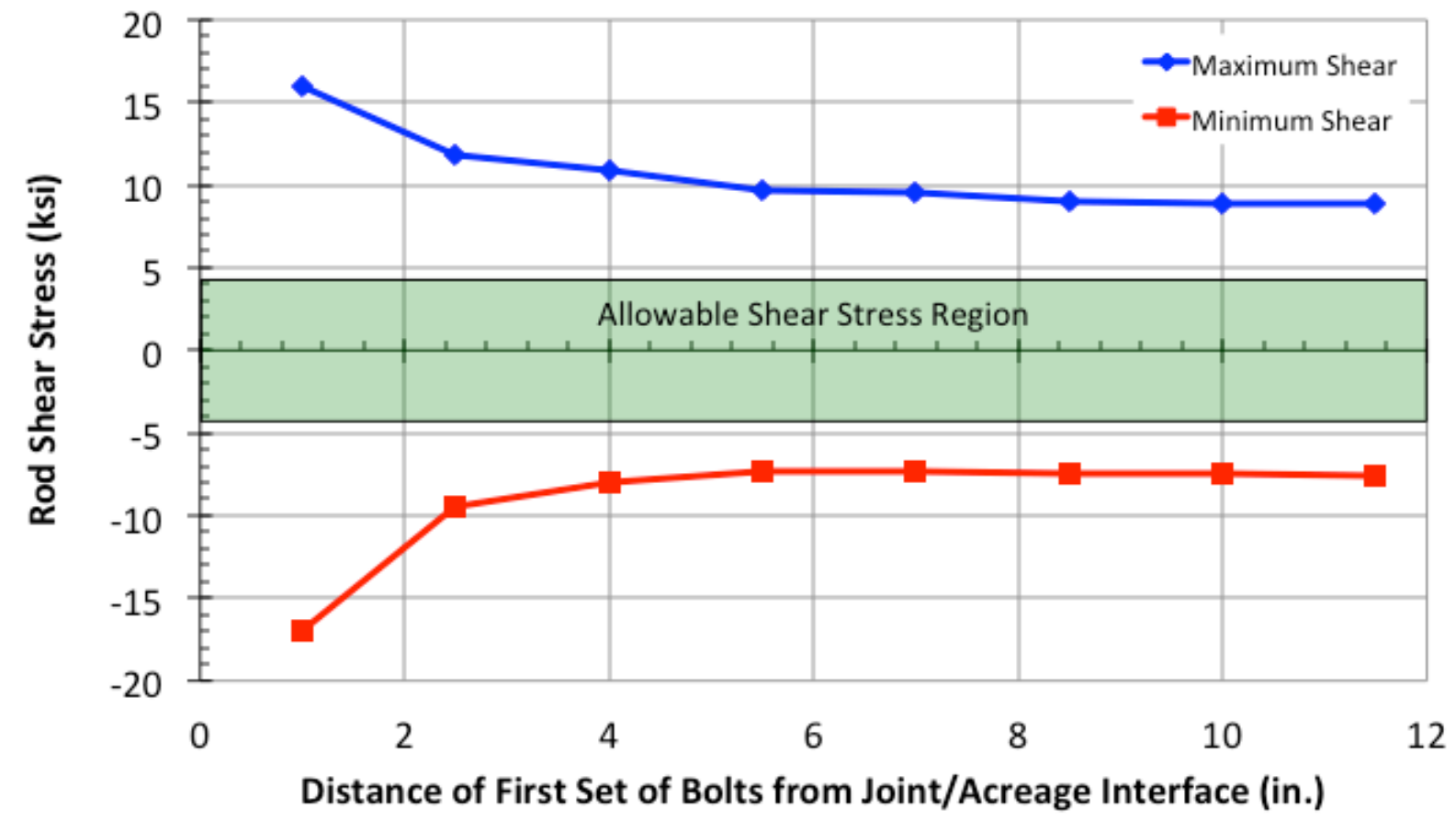

Figure 11. Rod shear stresses for baseline design with zero to seven sets of bolts removed (in negative zdirection, see Fig. 5).

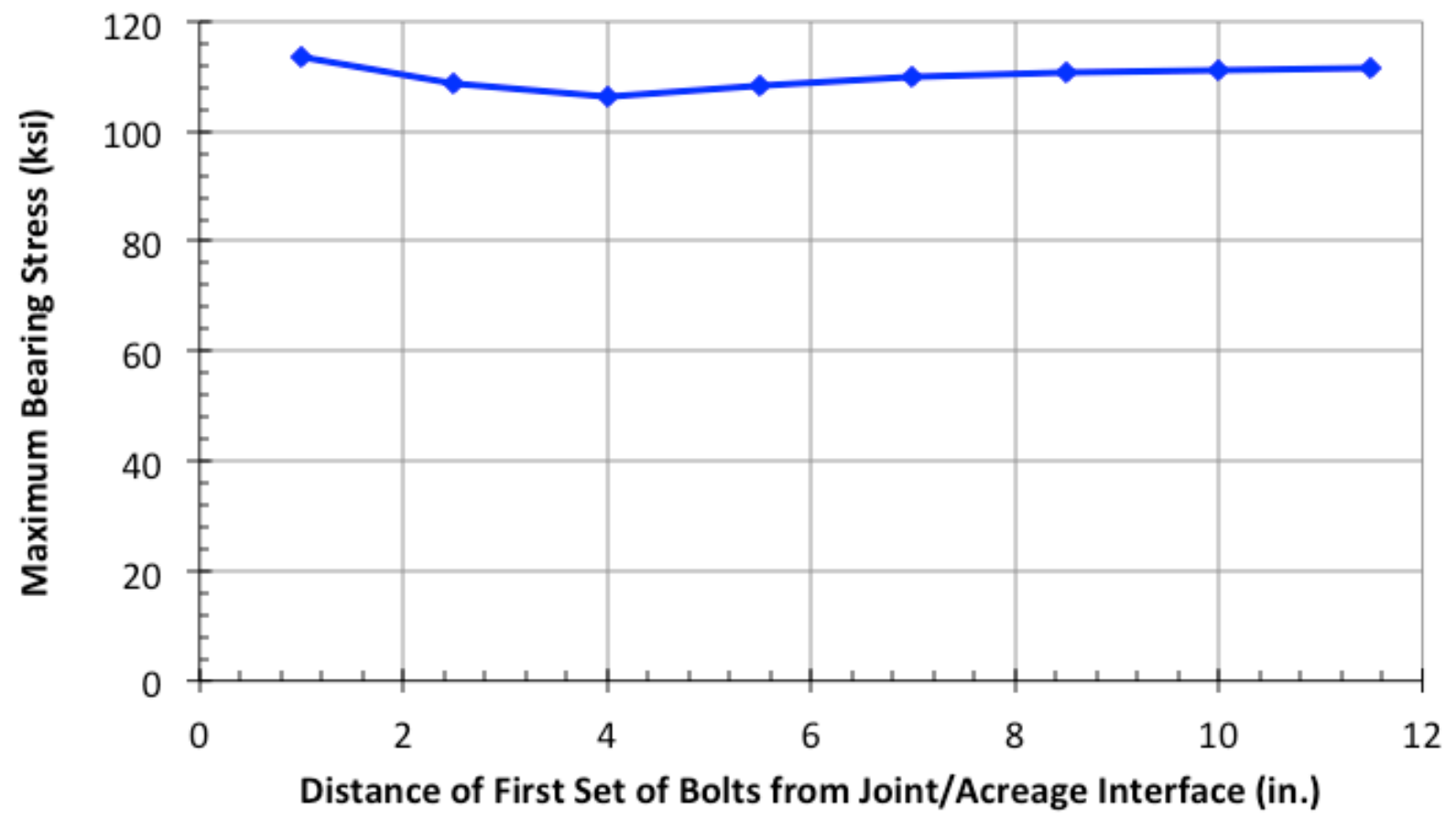

Figure 12. Maximum average bearing stresses for baseline-2 design with zero to seven sets of bolts removed (in negative z-direction, see Fig. 5). 


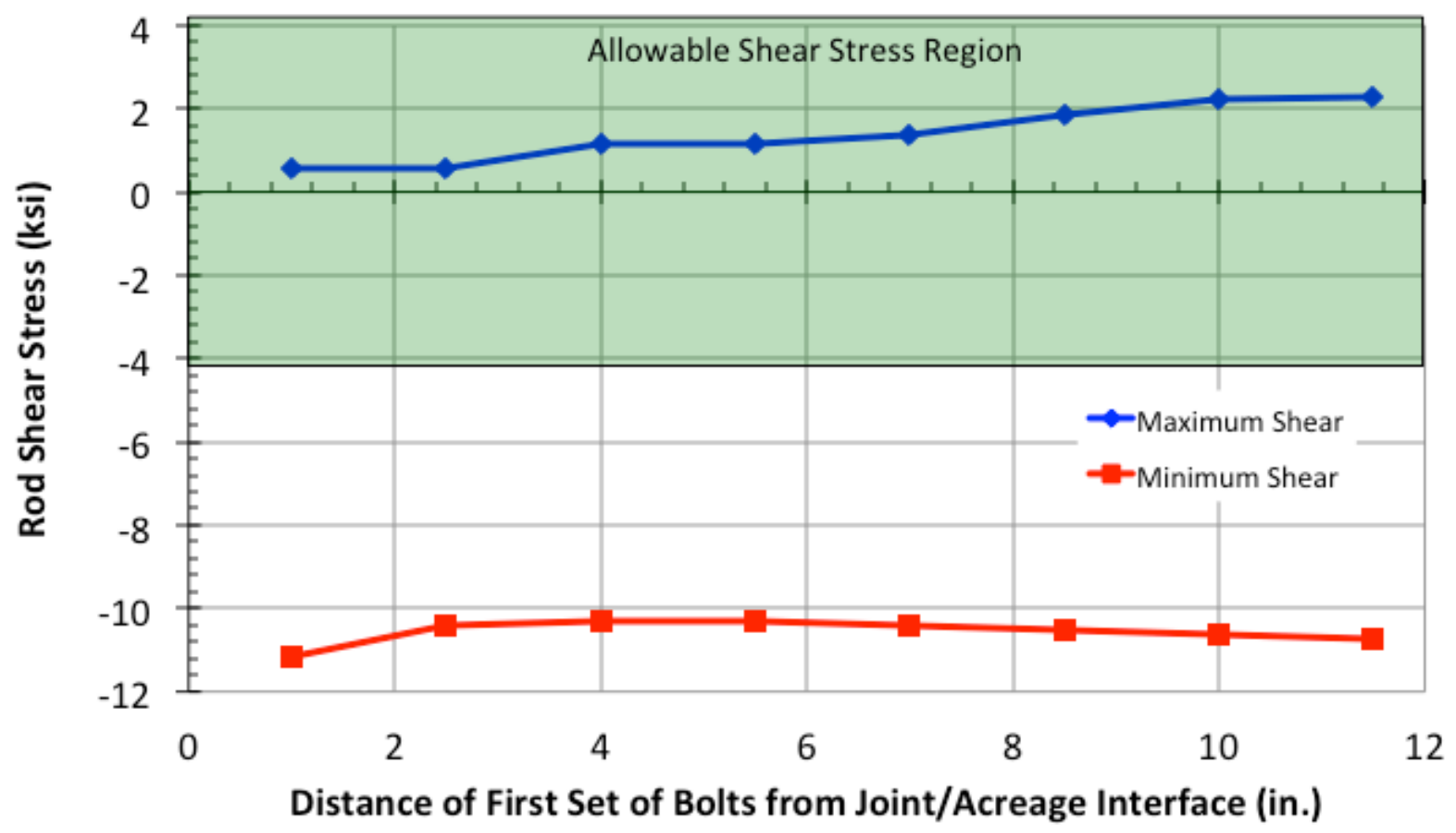

Figure 13. Rod shear stresses for baseline-2 design with zero to seven sets of bolts removed (in negative zdirection, see Fig. 5).

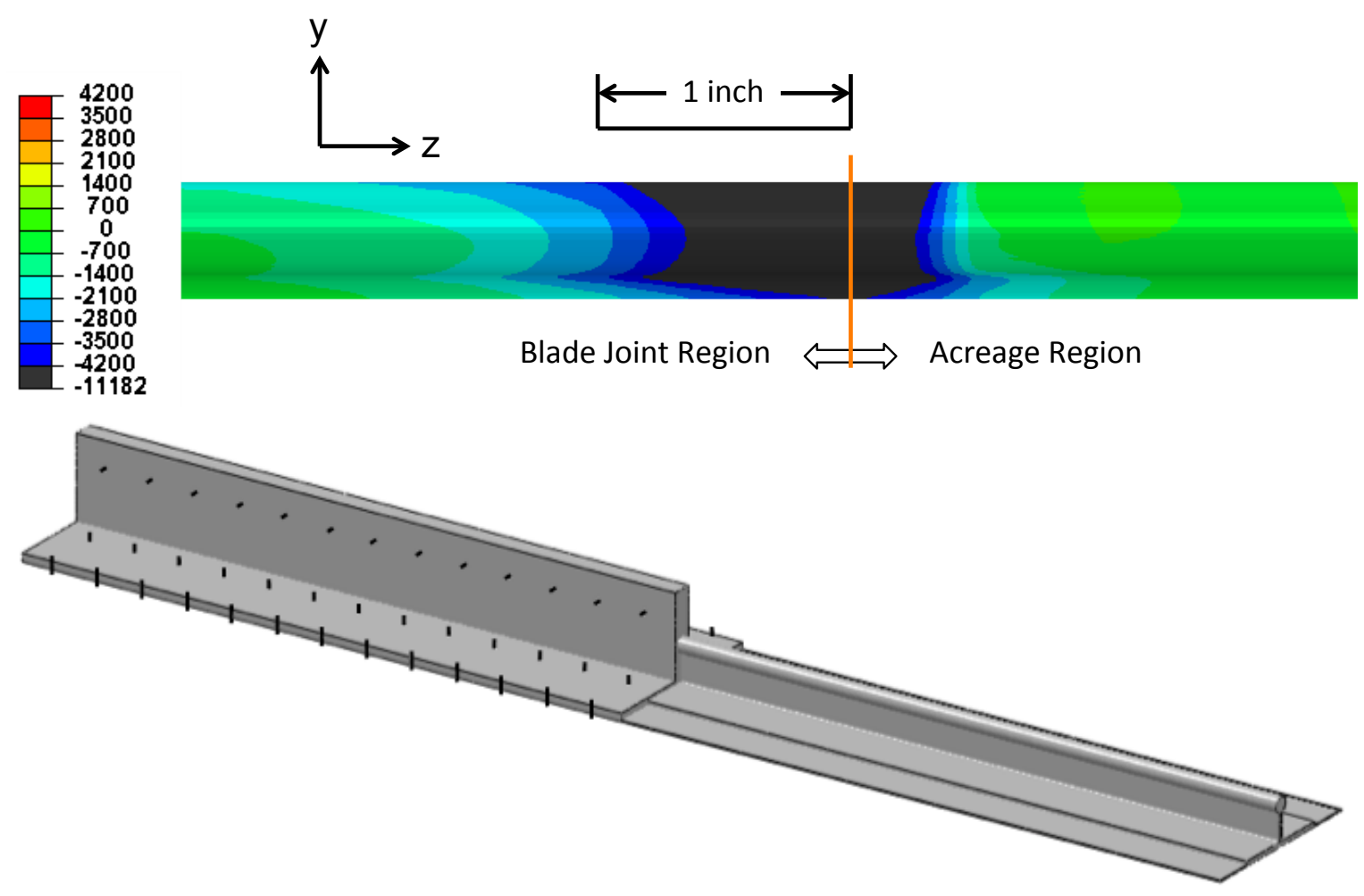

Figure 14. Rod shear stresses at blade joint/acreage intersection (see Fig. 5) and baseline-2 design with no bolt sets removed. 


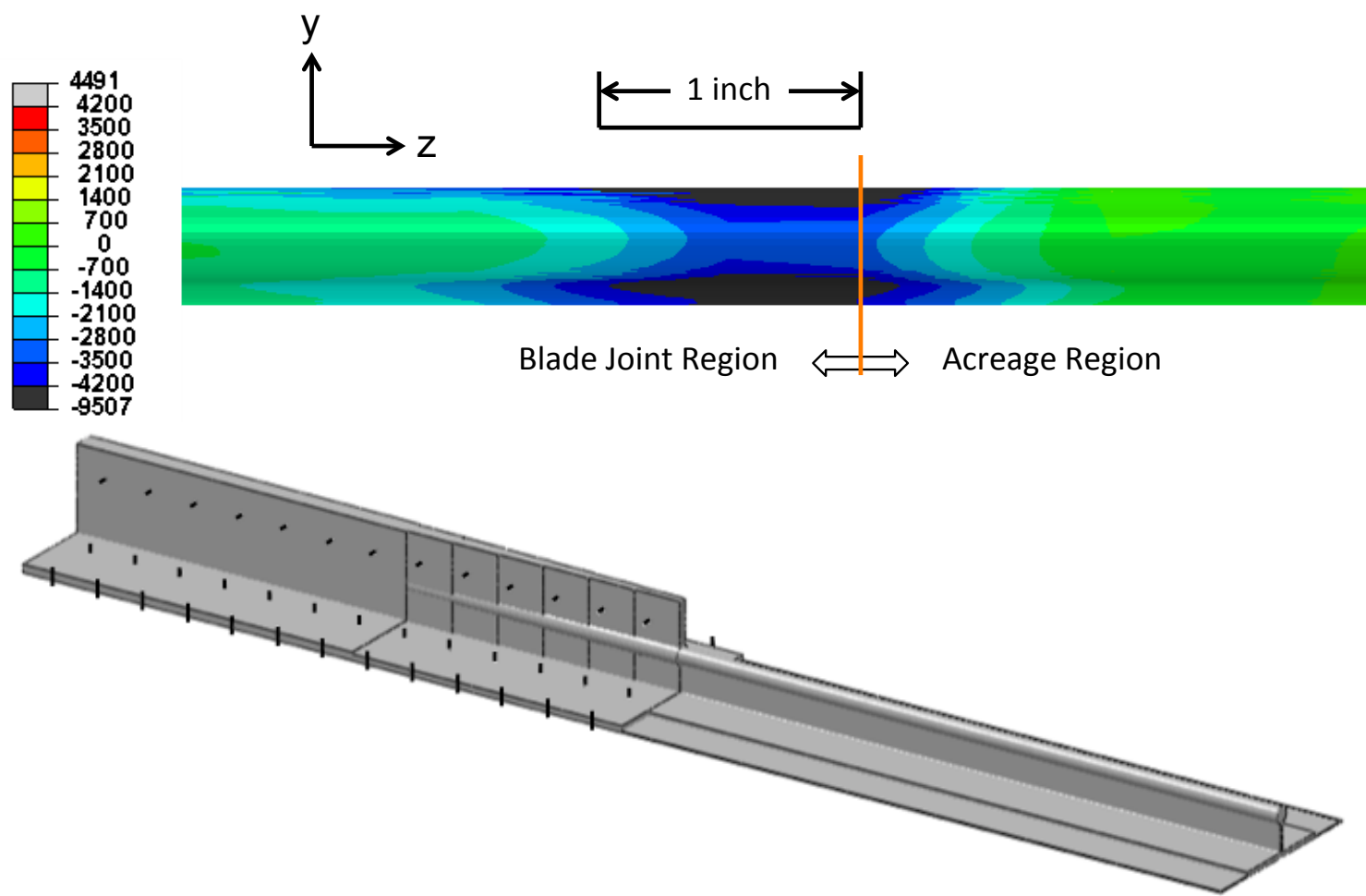

Figure 15. Rod shear stresses at blade joint/acreage intersection (see Fig. 5) and baseline-3 design with six stack drops and no bolt sets removed.

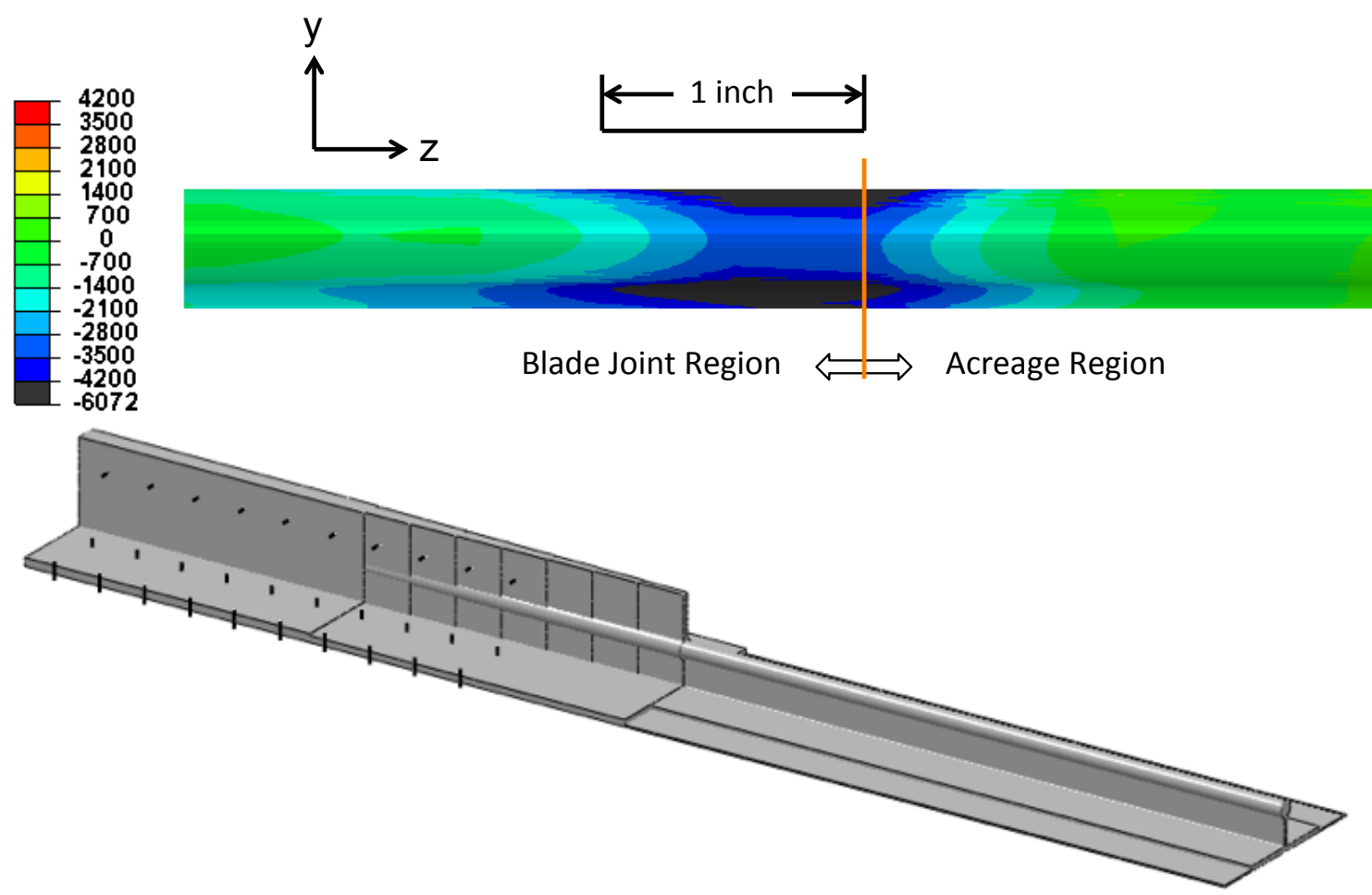

Figure 16. Rod shear stresses at blade joint/acreage intersection (see Fig. 5) and baseline-3 design with seven stack drops and three bolt sets removed. 


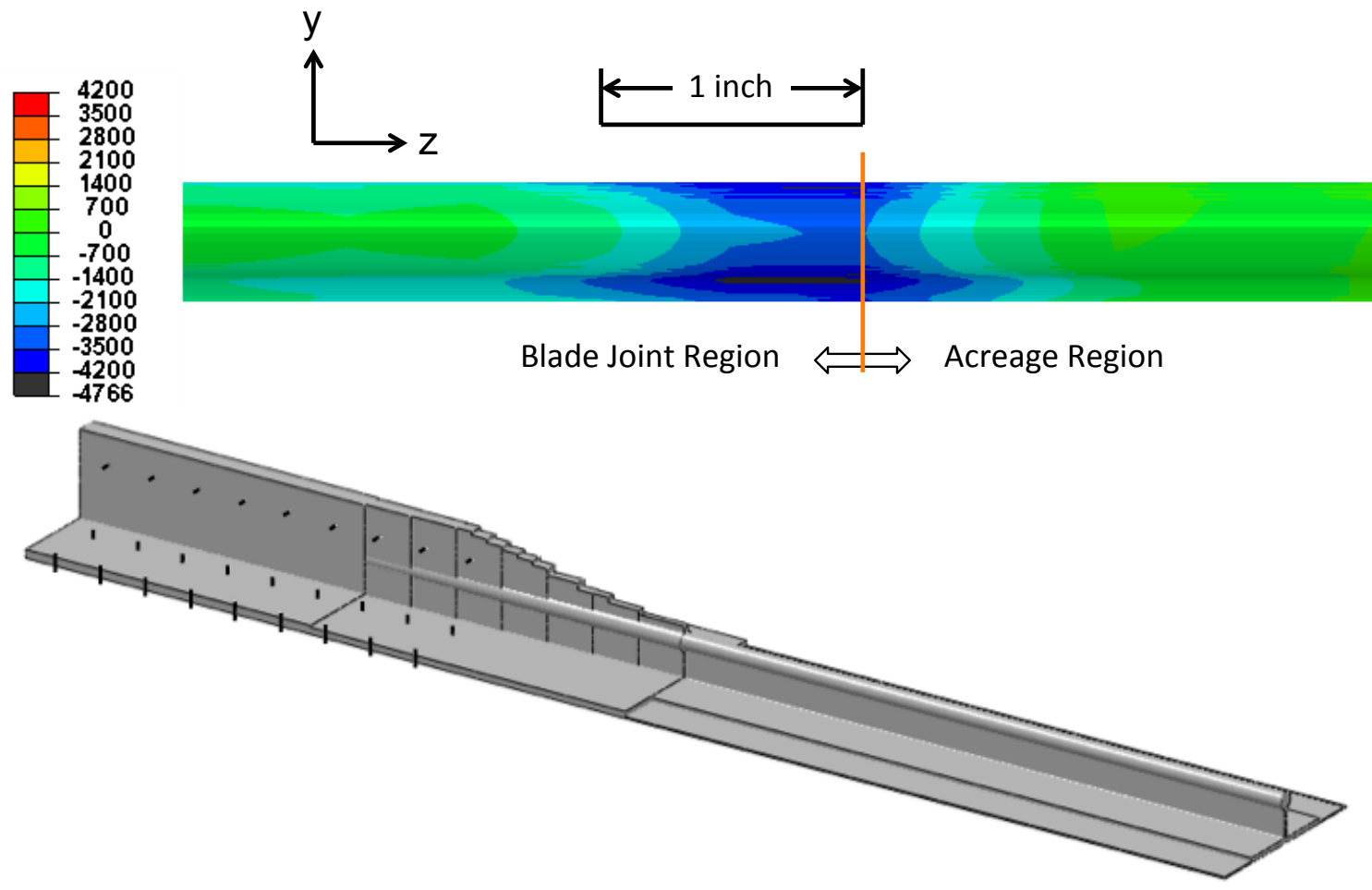

Figure 17. Rod shear stresses at blade joint/acreage intersection (see Fig. 5) and baseline-3 design with seven stack drops, four sets of bolts removed and tapered blade.

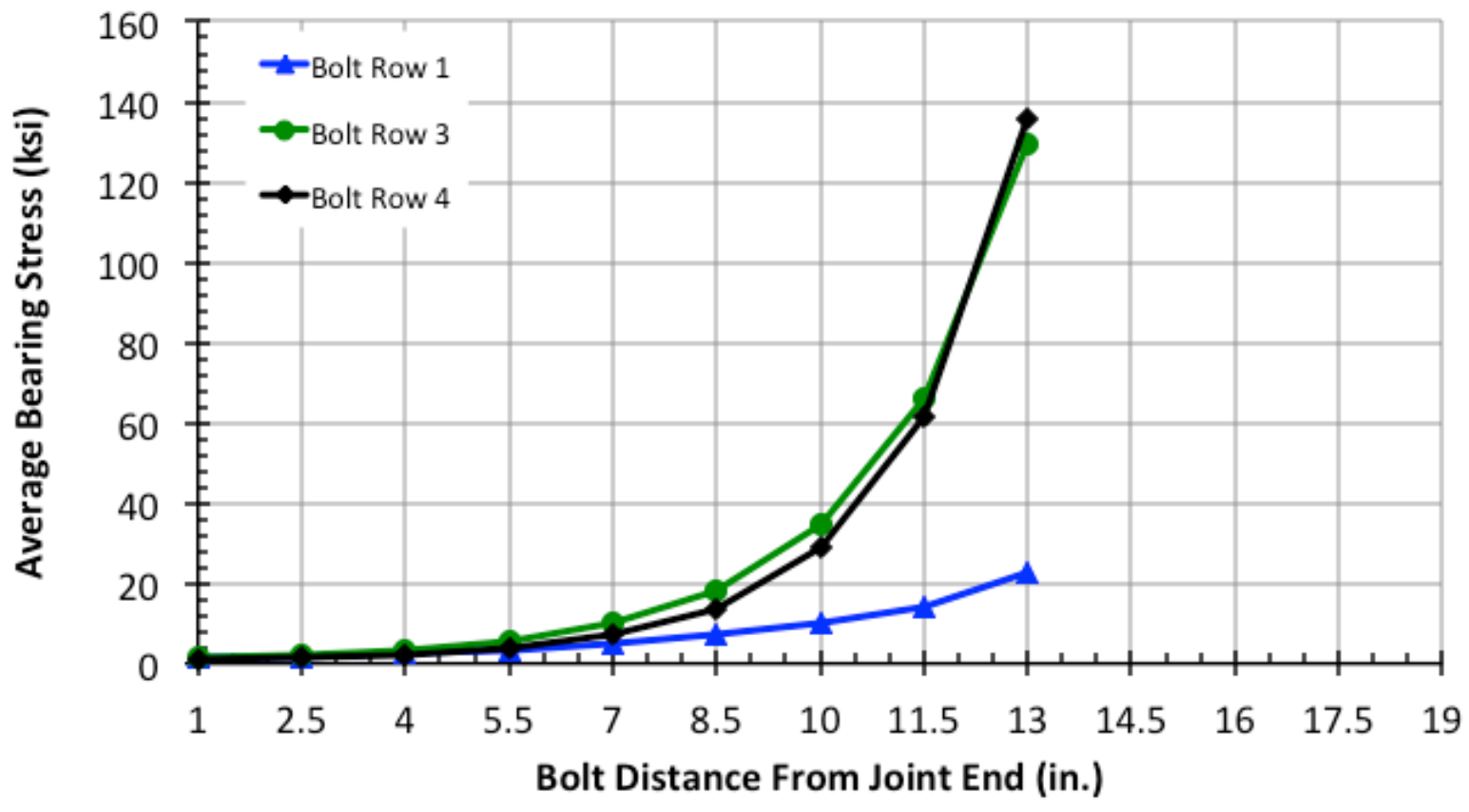

Figure 18. Bolt bearing stresses and baseline-3 design with seven stack drops, four sets of bolts removed and tapered blade (in z-direction, see Fig. 5). 


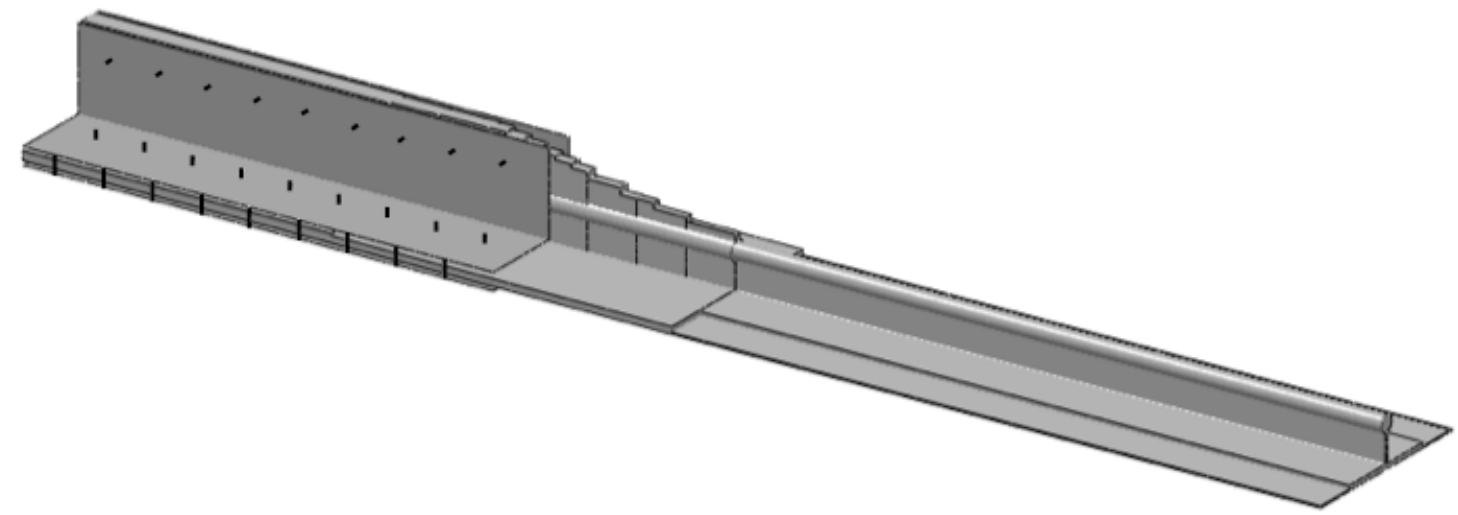

Figure 19. Model of Baseline-3 design with seven stack drops, four sets of bolts removed and tapered blade, including aluminum attachment structure. Element edges removed for clarity.

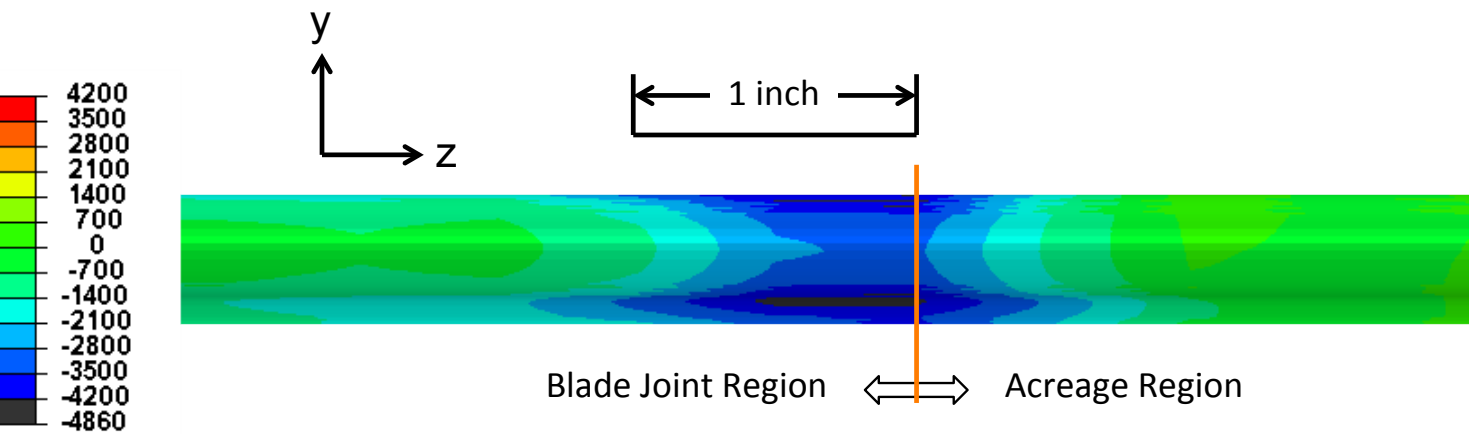

Figure 20. Rod shear stress distribution at blade joint/acreage intersection (see Fig. 5) for the model shown in Fig. 19. 


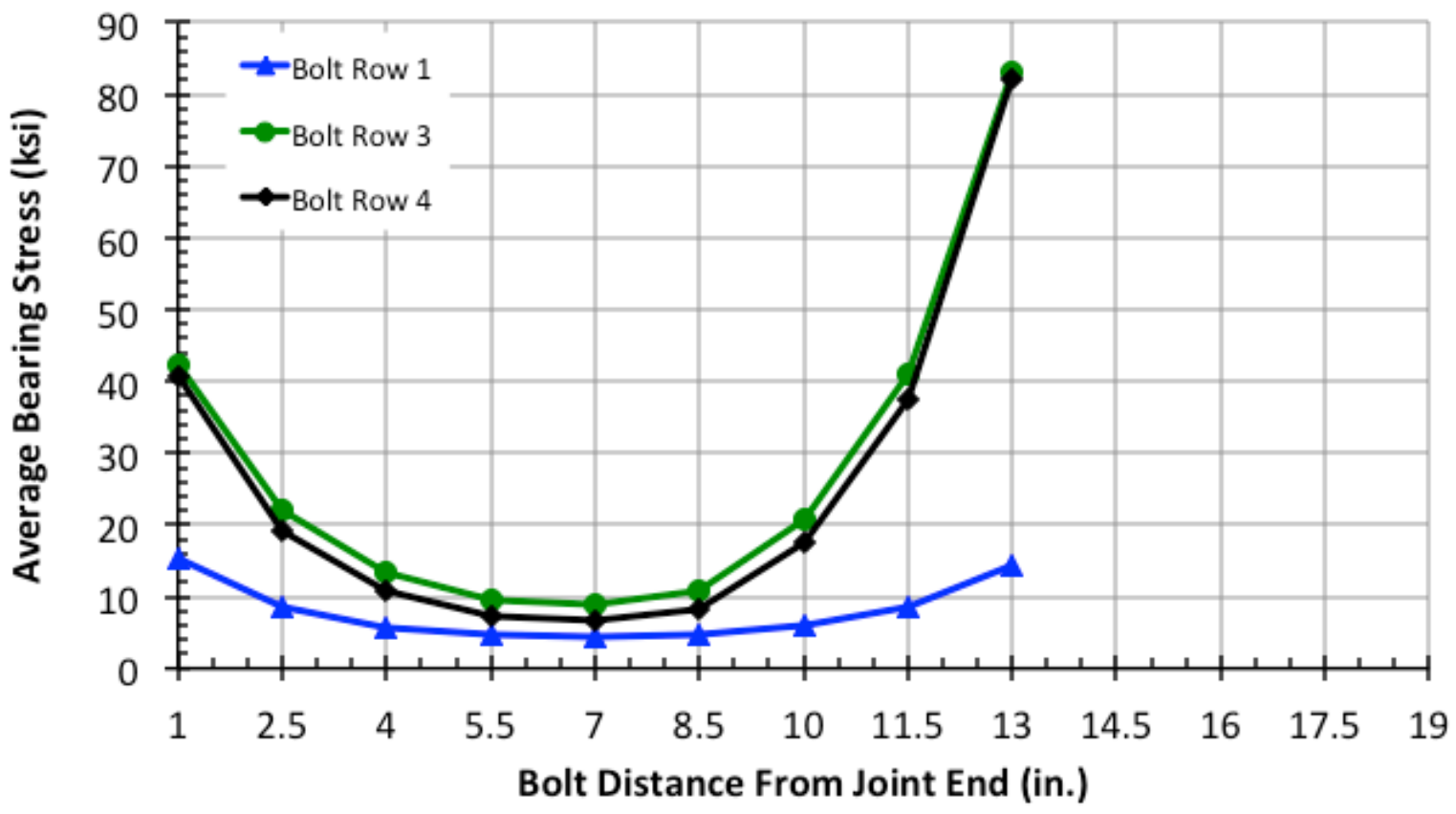

Figure 21. Bolt bearing stresses for the model shown in Fig. 19 (in z-direction, see Fig. 5).

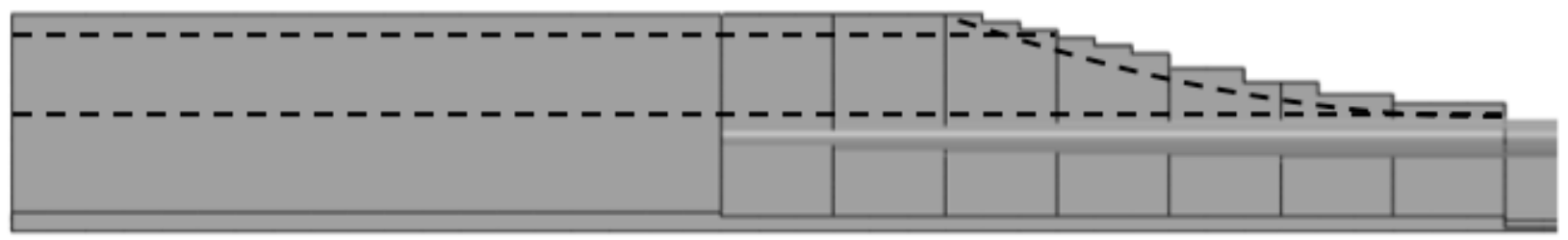

Figure 22. Locations of stitching above the rod in the joint blade with tapered height. 